\title{
Dynamics of a microbial biofilm in a rotating biological contactor for the treatment of winery effluent
}

\author{
G Coetzee, L Malandra, GM Wolfaardt and M Viljoen-Bloom* \\ Department of Microbiology, Stellenbosch University, Private Bag X1, Matieland 7602, South Africa
}

\begin{abstract}
Wastewater from wine-related industries is characterised by high variability in COD and pH. Disposal of these effluents with little or no treatment could lead to heavy financial penalties or pollution of soil and water resources. A pilot-scale rotating biological contactor (RBC) was evaluated for the treatment of winery effluent, with specific focus on the biofilms that formed on the RBC discs. On average, the RBC reduced the influent COD of the winery effluent by $23 \%$ (from $3828 \mathrm{mg} / \ell$ to $2910 \mathrm{mg} / \ell$ ) and increased the $\mathrm{pH}$ by 0.95 units (from 5.77 to 6.13 ) at an average retention time of $1 \mathrm{~h}$. Similar results were obtained during evaluations at a wine-bottling plant where thick active biofilms, containing mostly yeasts, formed on the discs and proved stable and resilient to various physical and chemical shocks.
\end{abstract}

Keywords: microbial biofilm, rotating biological contactor, winery effluent

\section{Introduction}

Wineries, distilleries and other wine-related industries produce large volumes of wastewater, characterised by variable volumes due to the seasonal nature of production, high in organic load, low in $\mathrm{pH}$ and having high carbon-to-nitrogen ratios. These types of wastewater may result in the pollution of soil, ground- and surface water (Radford, 2002) if the wastewater is disposed of without treatment. Regulatory bodies therefore impose restrictions on the nature, amount and means of disposal of winery wastewater, e.g. wastewater should have a $\mathrm{pH}$ of between 5.5 and 7.5 and a chemical oxygen demand (COD) below $75 \mathrm{mg} / \ell$ (National Water Act of South Africa, 1998).

Due to the organic nature of winery wastewater, biodegradation is a viable option for the treatment thereof. A variety of systems for the treatment of biodegradable wastewater have been developed(Ramasamy and Abbasi, 2000; Caixeta et al., 2002; Petruccioli et al., 2002) and the rotating biological contactor (RBC) is one that compares relatively well with other methods for the treatment of winery wastewater. It is flexible enough to endure fluctuating organic loads, requires little personal attention, is cheap to run and does not require too much land. Its operation is based on discs on a rotating shaft that allows the discs to be partly submerged in the effluent and support the biofilm responsible for the degradation of the organic compounds in the effluent. The RBC has also been used in the treatment of effluents produced by various industries such as gold mining (Stott et al., 2001) and domestic sewage treatment (Costley and Wallis, 2001; Gupta and Gupta, 2001; Tawfik et al., 2002). Its efficiency depends heavily on parameters such as the hydraulic retention time (Yeh et al., 1997), disc rotational speed and disc submergence (Lu et al., 1997), and the composition of the discs (Apilánez et al., 1998).

* To whom all correspondence should be addressed.

푱+2721 808-5859; fax:+2721 808-5846; e-mail: mv4@sun.ac.za

Received 20 November 2003; accepted in revised form 26 April 2004.
Since biofilms play an important role in the efficient treatment of effluent in biological reactors, knowledge of the adhesion, development and dynamics of biofilms is important. Previous work on a laboratory-scale RBC showed that the biofilm that formed during the treatment of winery effluent consisted mainly of yeast and a few bacterial species (Malandra et al., 2003). The most dominant yeast isolates in the microbial biofilms were Saccharomyces cerevisiae, Candida intermedia, Hanseniaspora uvarum and Pichia membranifaciens. All these species are naturally associated with grapes and/or water, and with the exception of $H$. uvarum, they are able to form either simple or elaborate pseudohyphae (Malandra et al., 2003). Extensive research has been done on bacterial biofilms (O'Toole et al., 2000; Watnick and Kolter, 2000), but information on fungal biofilms is seriously lacking. The objective of this study was to evaluate the efficiency of a pilot-scale RBC on-site at a local winery for the treatment of wine-cellar effluent and to study the dynamics of the biofilm that developed on the RBC discs.

\section{Materials and methods}

\section{Design and evaluation of the RBC}

A small-scale RBC was tested on-site at a local winery during the 2002 harvest season (January to April). The RBC consisted of a 250 l stainless steel trough with 52 polyurethane discs $(r=230$ $\mathrm{mm}$ ) on a rotating shaft (Fig. 1). The discs rotated at $6 \mathrm{r} \cdot \mathrm{min}^{-1}$ with $40 \%$ of their surface submerged. Winery wastewater was pumped into the RBC after the excess stems, grape skins and seeds had been removed, and the RBC operated at an average hydraulic retention time of $1 \mathrm{~h}$. Samples were taken at the inflow and outflow and the COD was determined spectrophotometrically based on Merck's chromo-sulphuric oxidation with the Thermoreaktor TR300 and Spectroquant Nova 60 (Merck, Darmstadt, Germany). The RBC was relocated in July 2002 to a bottling plant to be evaluated for its efficacy on wastewater generated during the bottling of wine products. 
Rotating Discs

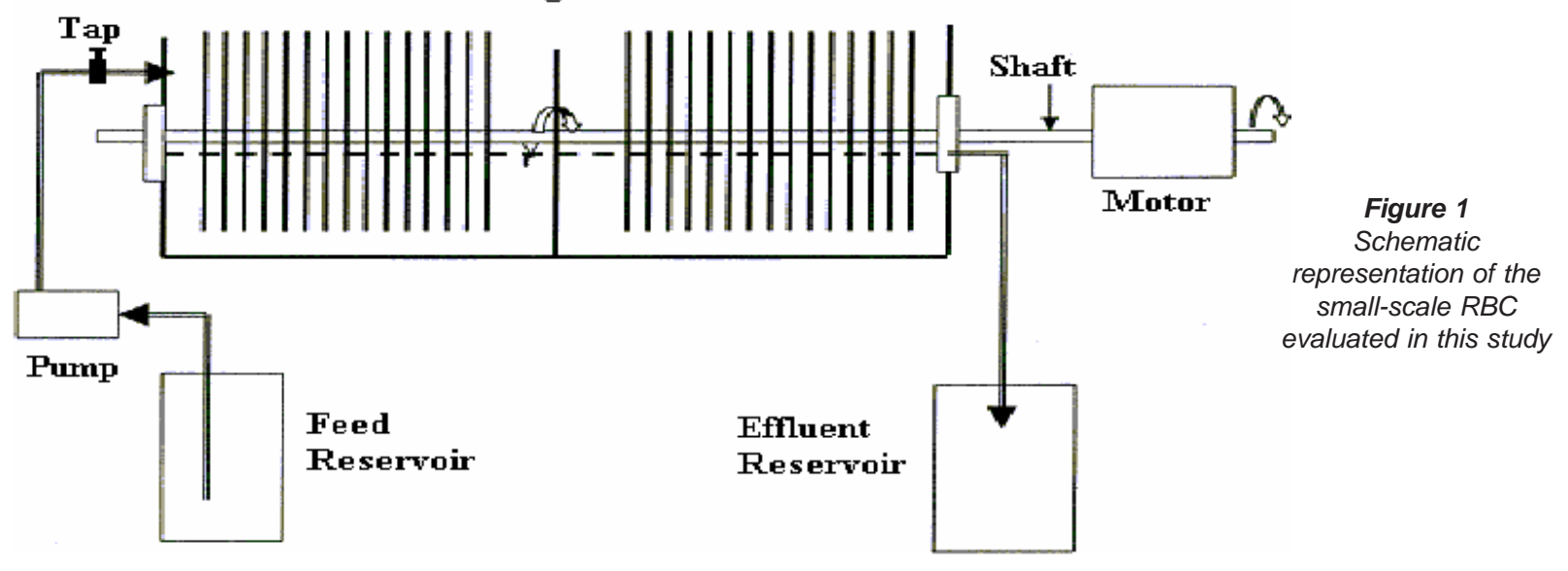

Biofilm formation by naturally occurring microorganisms in winery wastewater

Microscope slides were immersed in the winery wastewater inside the operating RBC for up to $30 \mathrm{~d}$. Slides were removed every 3 to $5 \mathrm{~d}$ and the biofilm on the slides was stained with acridine orange (Sigma Chemical Co., St. Louis, MO, USA) to be viewed under an epifluorescent microscope (Nikon Eclipse E400) at 600x magnification. Ten photographs were taken randomly on each slide and the average area covered by the biofilm was calculated using Scion Image (Scion Corporation, Maryland, USA).

\section{Recovery of biofilm after exposure to selected shocks}

Microscope slides were immersed for $9 \mathrm{~d}$ in $10 \%$ (v/v) diluted grape juice inside the laboratory-scale RBC (Malandra et al., 2003) while operating at a hydraulic retention time of $3 \mathrm{~h}$. The glass slides were removed and exposed to selected shocks for $1 \mathrm{~h}$. The slides were replaced and recovery of the biofilms was determined as percentage area covered (as described above). Each shock treatment was done in triplicate and included water-based solutions with $2.5 \% \mathrm{SO}_{2}$, 0.35\% NaOCl, 15\% ethanol, pH 12 (diluted $\mathrm{NaOH}$ ), pH 1.5 (diluted $\mathrm{HCl}$ ), and $60^{\circ} \mathrm{C}$.

\section{Adhesion of selected yeast isolates}

Strains of Saccharomyces cerevisiae, Williopsis saturnus, Hanseniasporauvarum, Candida intermedia, Candida inconspicua, Eremothecium gossypii and Pichia membranifaciens previously isolated from an RBC-biofilm (Malandra et al., 2003) were evaluated for their ability to adhere to a surface as described by Reynolds and Fink (2001). The isolates were inoculated onto the centre of YPD agar plates that contained either $0.3 \%$ agar and $0.25 \%$ glucose, or $0.3 \%$ agar and $2 \%$ glucose. Duplicate sets were incubated at $26^{\circ} \mathrm{C}$ and $30^{\circ} \mathrm{C}$.

\section{Results and discussion}

\section{On-site evaluation of the RBC}

The small-scale RBC was operated for three months during the 2002 harvest season. Within the first $6 \mathrm{~d}$ of operation, an average reduction of $41 \%$ (from $5988 \mathrm{~g} / \ell$ to $3550 \mathrm{~g} / \ell$ ) in the COD was obtained (Table 1 ). The variation in the COD of samples reflected the inconsistency of the winery wastewater due to different harvest

\begin{tabular}{|c|c|c|c|c|c|c|}
\hline \multicolumn{7}{|c|}{$\begin{array}{c}\text { TABLE } 1 \\
\text { COD and pH values obtained with RBC treatment on } \\
\text { site at a local winery }\end{array}$} \\
\hline \multirow[t]{2}{*}{ Day } & \multicolumn{2}{|c|}{$\mathrm{pH}$} & \multirow{2}{*}{$\begin{array}{l}\mathrm{pH} \\
\text { diffe- } \\
\text { rence }\end{array}$} & \multicolumn{2}{|c|}{ COD } & \multirow{2}{*}{$\begin{array}{l}\% \\
\text { degrada } \\
\text { tion }\end{array}$} \\
\hline & In & Out & & In & Out & \\
\hline 1 & 6.09 & 6.84 & 0.75 & 4770 & 2580 & 45.9 \\
\hline 5 & 4.7 & 6.02 & 1.32 & 7705 & 5925 & 23.1 \\
\hline 6 & 5.42 & 7.07 & 1.65 & 5490 & 2145 & 60.9 \\
\hline 16 & 8.5 & 4.57 & $\mathrm{Nd}$ & 5575 & 4570 & 18.0 \\
\hline 37 & 4.97 & 5.23 & 0.26 & 4135 & 3705 & 10.4 \\
\hline 41 & 4.11 & 4.82 & 0.71 & 3395 & 2575 & 24.2 \\
\hline 48 & 5.14 & 6.7 & 1.56 & 2100 & 1775 & 15.5 \\
\hline 50 & 4.13 & 4.47 & 0.34 & 3215 & 2705 & 15.9 \\
\hline 55 & 6.29 & 7.51 & 1.22 & 4555 & 4355 & 4.4 \\
\hline 58 & 4.03 & 4.54 & 0.51 & 3525 & 3345 & 5.1 \\
\hline 63 & 5.25 & 6.82 & 1.57 & 3070 & 2175 & 29.2 \\
\hline 65 & 5.26 & 6.32 & 1.06 & 2695 & 2500 & 7.2 \\
\hline 76 & 9.82 & 7.3 & $\mathrm{Nd}$ & 1720 & 975 & 43.3 \\
\hline 78 & 7.13 & 7.63 & 0.5 & 1645 & 1405 & 14.6 \\
\hline $\begin{array}{l}\text { Ave- } \\
\text { rage }\end{array}$ & 5.77 & 6.13 & 0.95 & 3238 & 2910 & 22.7 \\
\hline \multicolumn{7}{|c|}{ Nd, not determined } \\
\hline
\end{tabular}

loads, the presence of spent yeast or alcohol, contamination with detergents, etc. These factors influence the biodegradability of the organic matter in the wastewater and strongly affect the efficiency of the RBC. Despite these problems, an average decrease of $23 \%$ in the COD (from $3828 \mathrm{mg} / \ell$ to $2910 \mathrm{mg} / \ell$ ) and $\mathrm{pH}$ increase of 0.95 units (from 5.77 to $6.13 \mathrm{pH}$ units) were obtained at an average retention time of $1 \mathrm{~h}$ (Table 1 ). When the system was evaluated at a wine-bottling plant, it showed a $39 \%$ reduction in COD (from $6889 \mathrm{mg} / \ell$ to $4149 \mathrm{mg} / \ell$ ) and a $\mathrm{pH}$ increase of 0.83 units (from 4.6 to 5.4) while operating at retention times of between 1 to $4 \mathrm{~h}$ (data not shown). These results suggested that the RBC system was indeed performing at a reasonable efficiency and thus would provide a representative model for the biofilm studies.

Other systems applied to similar effluents produced higher efficiencies but at longer hydraulic retention times (HRT). For example, Ronquest and Britz (1999) found that a UASB operated 


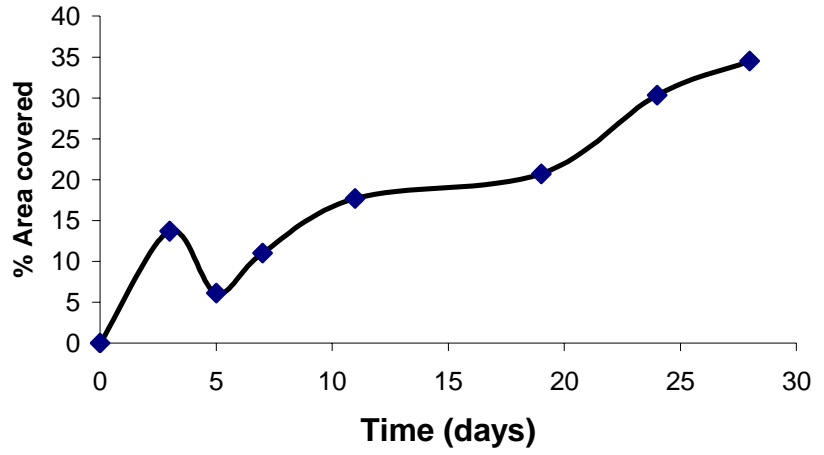

Figure 2

Quantitative analysis of the biofilm formation as determined by the area covered on the attachment surface

at a COD removal efficiency of $90 \%$ at an HRT of $24 \mathrm{~h}$ and an organic loading rate of $6.3 \mathrm{~kg} \mathrm{COD} \cdot \mathrm{m}^{-3} \cdot \mathrm{d}^{-1}$. At lower HRTs and an organic loading rate of $10.44 \mathrm{~kg} C O D \cdot \mathrm{m}^{-3} \cdot \mathrm{d}^{-1}$, the removal efficiency was more than $90 \%$, but the reactor became unstable and needed an extended operational period to recover. In a jet-loop activated sludge reactor tested on winery wastewater, the organic loading rates varied between $0.4 \mathrm{~kg} C O D \cdot \mathrm{m}^{-3} \cdot \mathrm{d}^{-1}$ and $5.9 \mathrm{~kg}$ COD $\cdot \mathrm{m}^{-3} \cdot \mathrm{d}^{-1}$ with HRTs varying between $2.1 \mathrm{~d}$ and $4.4 \mathrm{~d}$ (Petruccioli et al., 2002). COD removal efficiency was always higher than $90 \%$ with the organic loading rates of the final effluents ranging between $0.11 \mathrm{~kg}$ COD $\cdot \mathrm{m}^{-3} \cdot \mathrm{d}^{-1}$ and $0.3 \mathrm{~kg}$ COD $\cdot \mathrm{m}^{-3} \cdot \mathrm{d}^{-1}$.

\section{Biofilm growth by naturally occurring micro- organisms in the effluent}

After $30 \mathrm{~d}$, the biofilm covered approximately 35\% of the microscope slides submerged in the wastewater (Fig. 2). At that point, poor penetration of the fluorescent dye into the biofilm resulted in weak staining of the cells, suggesting the production and accumulation of dense extracellular polymeric substances (EPS) in the biofilm matrix. The area covered by the biofilm increased over time after an initial decrease at around Day 5. This could be ascribed to a possible lag phase in growth following their initial attachment during which the primary colonising cells may adapt to a sessile environment before they divide.

It was apparent that yeasts represented the bulk of the biofilm with some bacteria scarcely distributed in the biofilm (Fig. 3). The presence of both yeasts and bacteria in a biofilm is not a new phenomenon: S. cerevisiae has been shown to co-flocculate with beer-spoiling bacteria (Acetobacter, Hafnia protea, Lactobacillus brevis and Pediococcus) (Peng et al., 2001), and Candida albicans and Staphylococcus epidermidis co-existed in biofilms on prosthetic devices (Adam et al., 2002).

It should be pointed out that glass was used as attachment material in these experiments, while the discs in the RBC consisted of polyurethane. Glass is often used as model substrate in biofilm research that involves microscopy. Among the reasons for this are the optical properties of glass that allow comparison of images obtained by means of epi-illumination (i.e. epifluorescence used in this study) with conventional light microscopy, as well as the homogeneous nature of glass surfaces that facilitates direct comparison of results from unrelated studies. Because of the ubiquitous nature of biofilms, and subsequently the great variety of surface types on which biofilms develop in natural, industrial and medical settings, glass has become the substrate of choice in most studies. In fact, much of the work that contributed to our under-
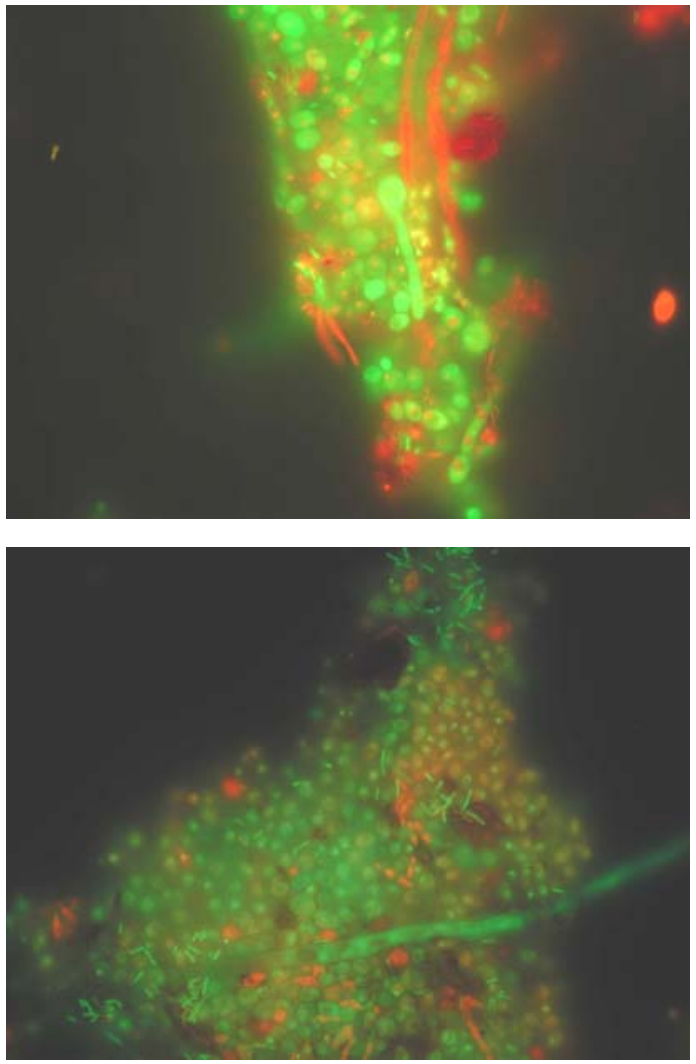

Figure 3

Epifluorescent microscopy photographs of representative biofilms stained with acridine orange dye showing that yeasts dominated the biofilms

standing of biofilm form and function was performed using glass as model substrate.

Because of the inherent difficulty to digitally separate individual cells in biofilms, most studies that analysed biofilm development used surface area coverage as measurement. Using this approach, Rashid et al. (2000) showed that mutants for the phosphatase kinase gene of a Pseudomonas strain formed biofilms with area coverage that was $10 \%$ of the wild type. Comparable results were obtained when they used other techniques, including biofilm thickness. Jackson et al. (2001) showed that biofilm areal calculations were reproduced within $10 \%$ error. Our results compare well with these and other studies. A noticeable difference between this and other studies is the fact that we measure biofilm development over relatively long periods of up to $30 \mathrm{~d}$, while studies such as reported by Jackson et al. (2001) cultivated biofilms for 4 d, and often fewer, before analysis.

\section{Recovery of biofilms after physical and chemical shocks}

To evaluate the resilience of RBC biofilms, a number of shocks representing practices that may occur at a winery, were introduced to determine their effect on the survival of the biofilm and its ability to recover from the shock. Treatment with household bleach ( $0.35 \%$ sodium hypochloride) had little effect, but all of the other treatments reduced the slide surface coverage (Fig. 4). The exposure to $\mathrm{pH} 12,60^{\circ} \mathrm{C}$ and $2.5 \% \mathrm{SO}_{2}$ initially reduced the biofilm by the largest margin compared to the other treatments. However, for all of the treatments, the biofilm was able to recover within $11 \mathrm{~d}$. As 


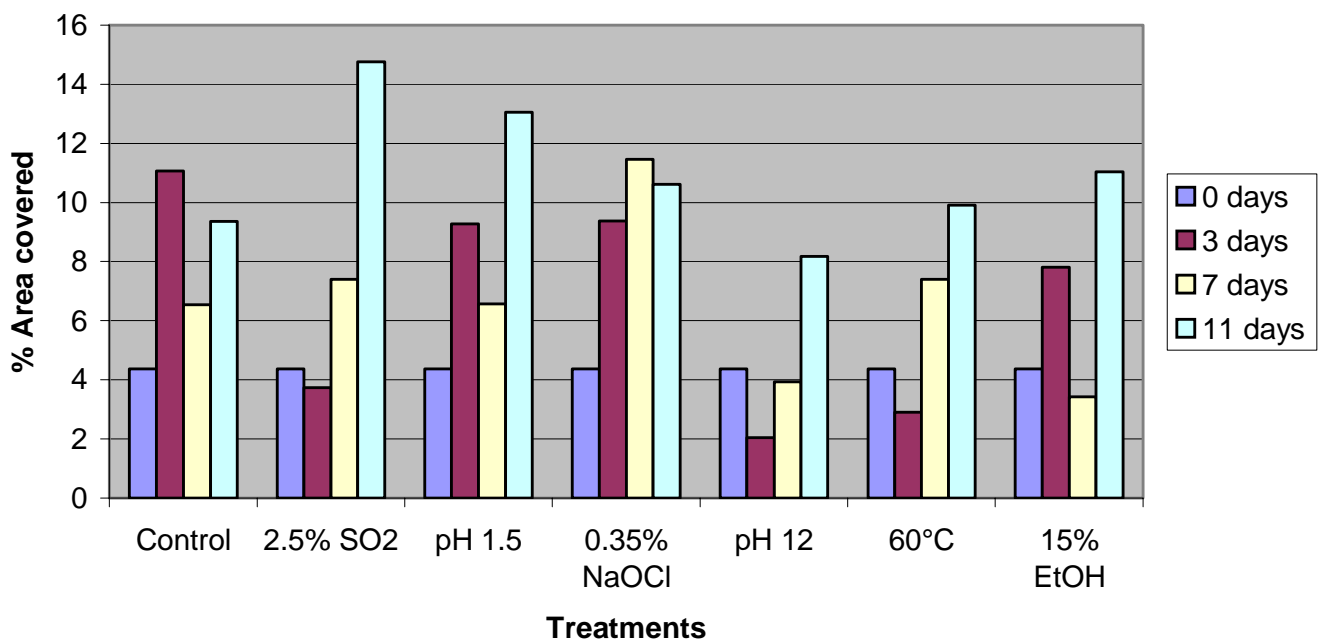

Figure 4

Recovery of biofilm after different physical or chemical shocks were introduced

discussed under the previous heading, determination of biofilm area coverage has become a widely applied method for quantifying biofilms. Even though it is not possible to determine biomass or biovolume without measured values for biofilm thickness, this approach has been demonstrated to provide valuable information on biofilm response to environmental conditions. As demonstrated in Fig. 4, biofilm area coverage showed a measurable response to introduced physical and chemical shocks. These results showed the ability of biofilms to recover following periods of stress. The implication of such recovery is not clear, and has increasingly become a topic of research. The role of biofilm formation as a survival mechanism among natural microbial communities has been discussed in numerous reviews.

Of relevance to this study is the question whether biofilms act as a buffer against fluctuations in growth conditions. Based on the results shown in Fig. 4, and the demonstrated events of biofilm behaviour that include attachment-growth-detachment, a realistic assumption is that because biofilms had not been completely removed by the various forms of treatment, they served as a source of viable cells when the stress was relieved. The importance of such a phenomenon will be particularly evident when the stress conditions kill the free-floating (planktonic) community. Industrial wastewaters, such as those associated with wine-making often contain chemicals, such as caustic soda, that may kill the more vulnerable planktonic cells. It is also possible that, when selected killing of sensitive populations occurs among the planktonic community, biofilms will have an important function in the maintenance of microbial diversity.

\section{Growth patterns of representative yeast strains}

Reynolds and Fink (2001) proposed that, similar to bacterial biofilms that require some kind of cell surface adhesin to initiate biofilm formation, S. cerevisiae may also require adhesins. Disruption of the S. cerevisiae FLO11 gene that encodes a cell surface glycoprotein required for adhesion to agar, also impaired the mutated S. cerevisiae strain's adhesion to polystyrene. The wildtype strain formed an elaborate flower-like mat when grown on YPD plates containing $0.3 \%$ agar. This phenotype was reduced in the FLO11 mutant, suggesting a link between biofilm formation and sliding motility. However, the ability to adhere to a surface does not necessarily mean it can develop into a stable mature biofilm. This was demonstrated by an S. cerevisiae strain that could adhere to prosthetic surfaces, but could not form a mature biofilm that is characterized by the production of extracellular material and special cellular functions (Chandra et al., 2001).
In this study, the growth patterns of seven yeast strains isolated from winery wastewater were investigated on soft agar plates containing $0.3 \%$ agar and either $0.25 \%$ or $2 \%$ glucose. The flowerlike growth pattern associated with sliding motility (Reynolds and Fink, 2001) seems to be strain-specific since it was not observed with the indigenous $S$. cerevisiae strain isolated from winery effluent. This may also be ascribed to the ploidy for the indigenous strain; increased ploidy also reduced mat formation in the S. cerevisiae strain investigated by Reynolds and Fink (2001), with a tetraploid strain showing almost no mat formation.

Only $H$. uvarum produced the elaborate flower-like growth pattern reported for S. cerevisiae (Reynolds and Fink, 2001) (Fig. 5). The spokes and hub exhibited by $H$. uvarum were more distinct at $26^{\circ} \mathrm{C}$ than $30^{\circ} \mathrm{C}$, but they developed much slower on $0.25 \%$ glucose at $26^{\circ} \mathrm{C}$. It was suggested that a decrease in the cell-surface adhesion in the low percentage agar plates would promote the movement of the cells across the plate (Reynolds and Fink, 2001). The yeast $P$. membranifaciens showed a completely different thread-like growth pattern on $2 \%$ glucose at both temperatures, covering the plates within $2 \mathrm{~d}$ (Fig. 5). The other yeast isolates only displayed lobed growth on the edge of the colony (data only shown for S. cerevisiae). All the other organisms used in this study are known to form either simple or elaborate pseudohyphae (Malandra et al., 2003), which may provide them with the ability to penetrate the substrate. The photomicrographs in Fig. 3 clearly show some of these pseudohyphal cells intertwined with other yeast and bacterial cells in the biofilm. Since $H$. uvarum is unable to form pseudohyphae, it is dependent on other mechanisms to associate itself with the biofilm and to secure its position in the complex matrix. This may be accomplished through its ability to form a mat on the extracellular polymeric substances (EPS) in the biofilm matrix.

\section{Conclusions}

Variations in the daily wine-cellar operations result in inconsistent wastewater characteristics that are not reflected by the COD alone. Factors such as different harvest loads, the presence of spent yeast or alcohol, contamination with detergents, etc., strongly influence the biodegradability of the organic matter in the wastewater and therefore the apparent efficiency of the RBC. Considering these variations and a short retention time of 1 to $4 \mathrm{~h}$, the RBC could be an effective primary treatment system to treat the peaks of high COD and acidity experienced during the harvest season and to lower the COD to more acceptable levels for secondary treatment by constructed wetlands or other biological, chemical or physio- 

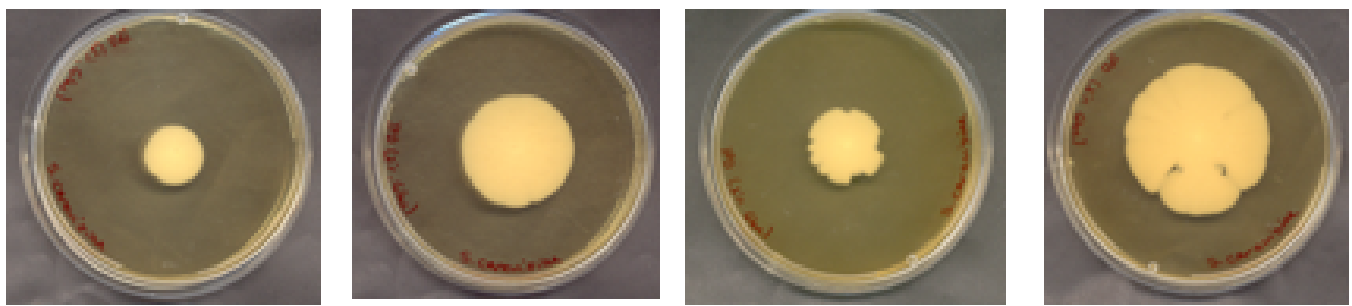

\section{Saccharomyces cerevisiae - $2 \%$ Glucose}
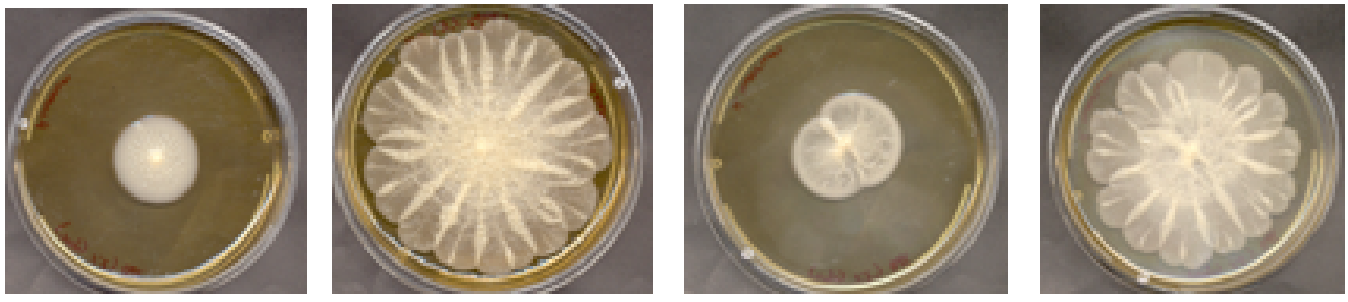

\section{Hanseniaspora uvanum - 2\% Glucose}
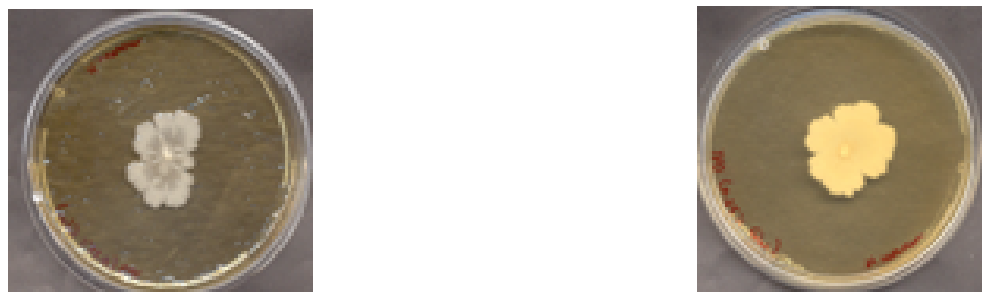

Hanseniaspora uvanum $\mathbf{- 0 . 2 5} \%$ Glucose

$26^{\circ} \mathrm{C}$

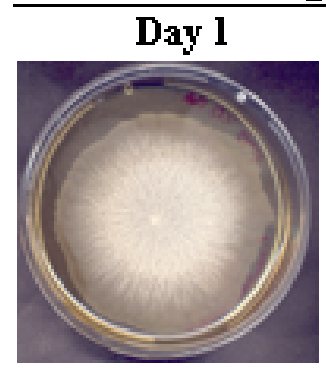

Day 2

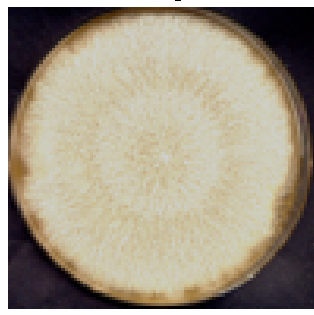

Pichia membranifaciens - 2\% Glucose $30^{\circ} \mathrm{C}$

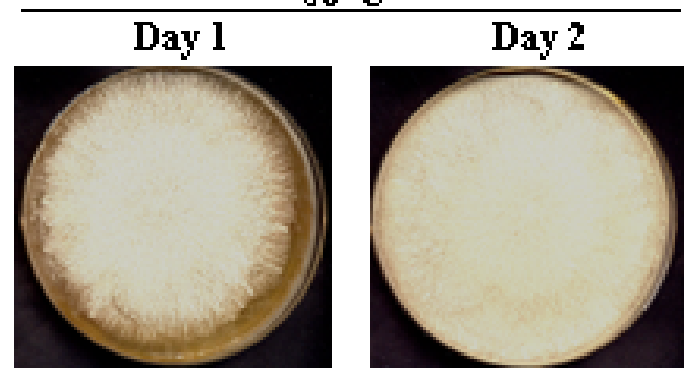

Figure 5

Mat formation by indigenous strains of S. cerevisiae, H. uvarum and $\mathrm{P}$. membranifaciens after growth on $2 \%$ glucose and $0.3 \%$ agar at $26^{\circ}$ and $30^{\circ} \mathrm{C}$ chemical processes.

The biofilms that developed on glass slides in the winery wastewater consisted largely of yeasts with bacteria being less prominent. These micro-organisms occurred naturally in the effluent and were adapted to the conditions within the winery wastewater. The biofilm also appeared to be stable, offering protection for the organisms within it. Evidence for such protection is the fact that the biofilms survived and rapidly recovered after being exposed to physical and chemical shocks.

Only one of the yeast isolates, H. uvarum, showed mat formation, suggesting that this yeast can adhere to surfaces and may therefore be able to initiate biofilm formation. The fact that the 
other isolates are known to form simple or elaborate pseudohyphae suggest that they may use alternative measures to associate with the biofilm and to secure their position within the matrix, e.g. by penetrating the EPS in the biofilm matrix. Although the results presented here shed some light on the organisms associated with industrial biofilms, more in-depth research is required to better understand the nature and dynamics of yeasts within microbial biofilms.

\section{Acknowledgements}

This work was supported by research grants from WINETECH, THRIP and the University of Stellenbosch. We thank the management and personnel of Distell (Pty) Ltd and Rostberg Bottlers (Pty) Ltd for their assistance with the evaluations.

\section{References}

ADAM B, BAILLIE GS and DOUGLAS LJ (2002) Mixed species biofilms of Candida albicans and Staphylococcus epidermidis. J. Med. Microbiol. 51(4) 344-349.

APILÁNEZ I, GUTIÈRREZ A and DÍAZ M (1998) Effect of surface materials on initial biofilm development. Bioresour. Technol. 66 (3) 225-230.

CAIXETA CET, CAMMAROTA MC and XAVIER AMF (2002) Slaughterhouse wastewater treatment: Evaluation of a new threephase separation system in a UASB reactor. Bioresour. Technol. 81 (1) 61-69.

CHANDRAJ, KUHN DM, MUKHERJEE PK, HOYER LL, MCCORMICK T and GHANNOUM MA (2001) Biofilm formation by the fungal pathogen Candida albicans: Development, architecture and drug resistance. J. Bacteriol. 183 (18) 5385-5394.

COSTLEY SC and WALLIS FM (2001) Bioremediation of heavy metals in a synthetic wastewater using a biological contactor. Water Res. 35 (15) 3715-3723.

GUPTA AB and GUPTA SK (2001) Simultaneous carbon and nitrogen removal from high strength domestic wastewater in an aerobic RBC biofilm. Water Res. 35 (7) 1714-1722.

JACKSON G, BEYENAL H, REES WM and LEWANDOWSKI Z (2001) Growing reproducible biofilms with respect to structure and viable cell counts. J. Microbiol. Meth. 47 (1) 1-10.

LU C, LI H and LEE LY (1997) Effects of disc rotational speed and submergence on the performance of an anaerobic rotating biological contactor. Environ. Int. 23(2) 253-263.

MALANDRA L, WOLFAARDT GM, ZIETSMAN JJ and VILJOENBLOOM M (2003) Microbiology of a rotating biological contactor for winery wastewater treatment. Water Res. 37 (17) 4125-4134.

NATIONAL WATER ACT (1998) Act 36 of 1998. Republic of South Africa Government Gazette. 39819182.

O'TOOLE G, KAPLAN HB and KOLTER R (2000) Biofilm formation as microbial development. Ann. Rev. Microbiol. 54 49-79.

PENG X, SUN J, ISERENTANT D, MICHIELS C and VERACHTERT H (2001) Flocculation and coflocculation of bacteria by yeasts. Appl. Microbiol. Biotechnol. 55 (6) 777-781.

PETRUCCIOLI M, DUARTE JC, EUSEBIO A and FEDERICI F (2002) Aerobic treatment of winery waste-water using a jet-loop activated sludge reactor. Process. Biochem. 37 (8) 821-829.

RADFORD A (2002) The composition of winery and distillery wastewater and effects on soil and water. Cellar and Distillery Effluent Seminar. ARC-Infruitec Stellenbosch.

RAMASAMY EV and ABBASI SA (2000) Energy recovery from dairy waste- waters: impacts of biofilm support systems on anaerobic CST reactors. Appl. Energy 65 91-98.

RASHID MH, RUMBAUGH K, PASSADOR L, DAVIES DG, HAMOOD AN, IGLEWSKI BH and KORNBERG A (2000) Polyphosphate kinase is essential for biofilm development, quorum sensing, and virulence of Pseudomonas aeruginosa. Proc. Natl. Acad. Sci. 97 (17) 9636-9641.

REYNOLDS TB and FINK GR (2001) Baker's yeast, a model for fungal biofilm formation. Sci. 291 (5505) 878-881.

RONQUEST LC and BRITZ TJ (1999) Influence of lower substrate $\mathrm{pH}$ and retention time on the efficiency of a UASB bioreactor treating winery waste water. S. Afr. J. Enol. Vitic. 20 (1) 35-41.

STOTT MB, FRANZMANN PD, ZAPPIA LR, WATLING HR, QUAN LP, CLARK BJ, HOUCHIN MR, MILLER PC and WILLIAMS TL (2001) Thiocyanate removal from saline CIP process water by a rotating biological contactor, with reuse of the water for bioleaching. Hydromet. 62 (2) 93-105.

TAWFIK A, KLAPWIJK B, EL-GOHARY F and LETTINGA G (2002) Treatment of anaerobically pre-treated domestic sewage by a rotating biological contactor. Water Res. 36 (1) 147-155.

WATNICK P and KOLTER R (2000) Biofilm, city of microbes. J. Bacteriol. 182 (1) 2675-2679.

YEH AC, LU C and LIN M (1997) Performance of an anaerobic rotating biological contactor: effects of flow rate and influent organic strength. Water Res. 31 (6) 1251-1260. 